\title{
Comparison of the Pharmacokinetic-Pharmacodynamic Relationships of Two Darbepoetin Alfa Formulations in Healthy Male Volunteers
}

\author{
Seokuee Kim ${ }^{1} \cdot$ Taegon Hong ${ }^{2} \cdot$ Jae-Wook Ko ${ }^{1}$ Wooseong Huh ${ }^{1,3} \cdot$ Jung-Ryul Kim ${ }^{1,4}(\mathbb{C}$
}

Published online: 1 December 2018

(c) The Author(s) 2018

\begin{abstract}
Objective This study compared the pharmacokinetic (PK), pharmacodynamic (PD), and safety properties of the test (CJ40001) and reference $\left(\mathrm{NESP}^{\circledR}\right.$ ) versions of darbepoetin alfa following a single subcutaneous (SC) or intravenous (IV) administration in healthy male subjects.

Methods A single-blind, randomized, single-dose, two-period, two-intervention crossover study was conducted, with two separate parts consisting of SC or IV administration. In each period, either a test or reference product was administered via the SC or IV route. Serial blood samples for PK analysis and the reticulocyte, hematocrit, hemoglobin, and red blood cell counts for PD analysis were collected for up to 360 or $264 \mathrm{~h}$ after SC or IV administration, respectively. The PK and PD parameters were calculated using non-compartmental methods. The $90 \%$ confidence intervals of the geometric mean ratios for the PK and PD parameters between the two interventions were estimated. Safety and anti-drug antibody profile assessments were performed.

Results The mean darbepoetin alfa concentration-time profiles were comparable between the two products for SC and IV administration. Additionally, the PD and safety profiles were similar between the two products. Anti-drug antibody reactivity was negative for all samples from both intervention groups for SC and IV administration. The time-matched serum darbepoetin alfa concentration and the PD markers presented a counter-clockwise hysteresis, which suggests a time delay between the exposure and response.
\end{abstract}

Conclusion The test and reference darbepoetin alfa formulations had similar PK, PD, and safety profiles. Thus, it is expected that the two formulations are able to be used interchangeably in clinical settings.

ClinicalTrials.gov Identifier: NCT03542916.

Wooseong Huh

wooseong.huh@samsung.com

$\triangle$ Jung-Ryul Kim

jungryul.kim@samsung.com

1 Department of Clinical Pharmacology and Therapeutics, Samsung Medical Center, Seoul, Republic of Korea

2 Department of Clinical Pharmacology, Severance Hospital, Yonsei University College of Medicine, Seoul, Republic of Korea

3 Division of Nephrology, Department of Medicine, Samsung Medical Center, Sungkyunkwan University School of Medicine, Seoul, Republic of Korea

4 Department of Clinical Research Design and Evaluation, SAIHST, Sungkyunkwan University, Seoul, Republic of Korea

\section{Key Points}

This is the first report on the pharmacokinetic and pharmacodynamic characteristics of CJ-40001, a biosimilar darbepoetin alfa.

Based on the comparable pharmacokinetics, pharmacodynamics, and safety profiles of the test and reference darbepoetin alfa, it is expected that they can be used interchangeably.

\section{Introduction}

Anemia is a common finding in patients with chronic kidney disease (CKD) and in those with cancer who are receiving multiple-cycle chemotherapy [1-6]. The anemia associated 
with CKD has a multifactorial pathology that includes relative erythropoietin (EPO) deficiency, uremic-induced inhibitors of erythropoiesis, shortened erythrocyte survival, and disordered iron homeostasis [2]. The etiology of chemotherapy-related anemia is also multifactorial, resulting from the myelosuppressive effects of chemotherapy and the direct effects on the renal tubules, decreasing the production of the EPO [7].

EPO is a glycoprotein hormone that regulates erythropoiesis and plays a crucial role in erythrocyte production and maturation $[1,8,9]$. EPO is mainly produced in the peritubular cells of the kidneys in adults and in hepatocytes in the fetus [1]. Hypoxia leads to an increase in EPO production, and EPO controls red blood cell (RBC) production $[1,10]$. The management of CKD or chemotherapy-related anemia was revolutionized by the introduction of recombinant human EPO (rHuEPO), one of the key medications for these types of anemias [1, 2, 11-13]. However, according to the recommended use of rHuEPO, patients should receive the medicine two to three times a week via an invasive route [subcutaneous (SC) or intravenous (IV) injection] [14]. Difficulties relating to this type and frequency of administration led to the development of molecules with improved in vivo bioactivity that can reduce the frequency of administration. This research resulted in the discovery and development of the second-generation rHuEPO, darbepoetin alfa (NESP ${ }^{\circledR}$, Kyowa Hakko Kirin Co., Ltd., Tokyo, Japan), which can be administered less frequently than the first-generation rHuEPO [14, 15], and the US Food and Drug Administration (FDA) approved darbepoetin alfa for the treatment of CKD-associated anemia in 2001 [16].

The pharmacokinetic (PK) and pharmacodynamic (PD) relationship in reference darbepoetin alfa following intensive sampling has rarely been reported [17]. In addition, it has also not been reported whether such studies have been conducted under conditions where potential confounding factors were controlled. We therefore conducted a study of the PK-PD relationship and safety profile of test darbepoetin alfa (CJ-40001, CJ HealthCare Corp., Seoul, Korea) compared with that of the reference darbepoetin alfa $\left(\mathrm{NESP}^{\circledR}\right)$ given via two administration routes, SC and IV, in healthy volunteers.

\section{Methods}

\subsection{Study Design}

This study was conducted in accordance with the ethical principles of the 1964 Helsinki Declaration and the Korean Good Clinical Practices [18]. This study was a single-blind, randomized, single-dose, two-period, two-intervention crossover study, with two separate parts (Fig. 1). Before enrollment and any study-related procedures were performed, informed consent was obtained from all individual subjects included in the study. In each part, subjects who were eligible based on the inclusion/exclusion criteria were randomized to one of two sequence groups where they would each be administered a single dose of reference and test drug according to the sequence allocated to them.

Healthy male adults aged $19-55$ years with a body mass index of $19-28 \mathrm{~kg} / \mathrm{m}^{2}$ were eligible. Subjects who showed at least one of the following clinical laboratory results were excluded: blood hemoglobin $(\mathrm{Hb})$ value $<13$ or $>17 \mathrm{~g} / \mathrm{dL}$; blood reticulocyte (Ret) value more than the upper reference limit (2\%); and/or blood vitamin $\mathrm{B}_{12}(211 \mathrm{pg} / \mathrm{mL})$, ferritin $(22 \mathrm{ng} / \mathrm{mL})$, or transferrin $(200 \mathrm{mg} / \mathrm{dL})$ value less than the lower reference limit. Major exclusion criteria were the

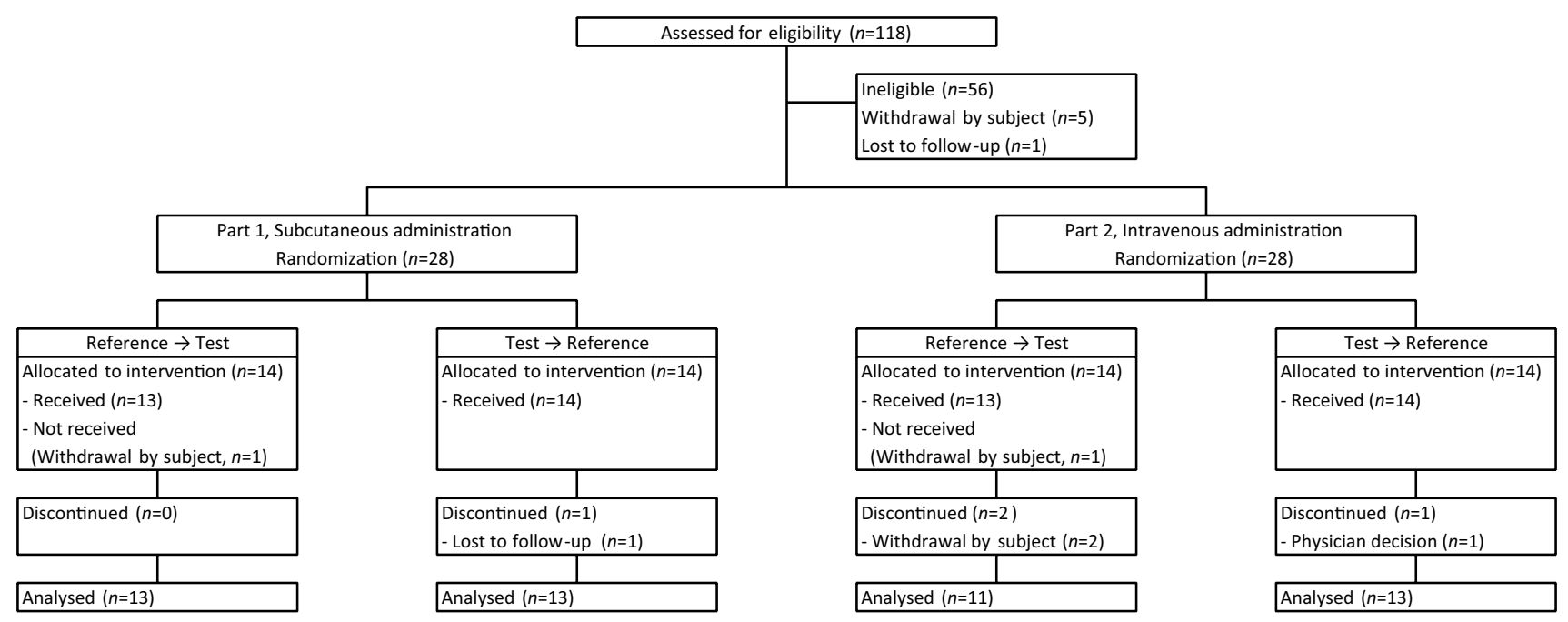

Fig. 1 Study design and subject disposition 
following: history of drug abuse; history of major illness; positive status for HIV, syphilis, or hepatitis B or C; and clinically abnormal laboratory and 12-lead electrocardiography (ECG) safety parameters.

The intra-subject variability of the maximum serum concentration $\left(C_{\max }\right)$ and the area under the concentration-time curve (AUC) to the last measurable concentration $\left(\mathrm{AUC}_{\text {last }}\right)$ was assumed to be $20 \%$ and $15 \%$, respectively, based on the previous report of darbepoetin alfa [19]. With a sample size of 20 , a difference of $20 \%$ in the log-transformed PK parameters could be detected with a $90 \%$ test power at a significance level of 0.05 . The total number of subjects for each part was 28 (14 subjects per sequence group), which could accommodate an approximate dropout rate of $25 \%$ [20].

The enrolled subjects were randomly allocated to one of the two sequences and received a single SC or IV injection of $60 \mu \mathrm{g}$ of either the test drug (CJ-40001; CJ HealthCare Corp.) or the reference drug (NESP ${ }^{\circledR}$ Prefilled Syringe 60; Kyowa Hakko Kirin Co., Ltd.) after $10 \mathrm{~h}$ of fasting (Fig. 1). Depending on the part, the study drug was administered via the SC or IV route on the upper arm. A washout period of 35-49 days (representing at least a five-fold terminal elimination half-life $\left(t_{1 / 2}\right)$ of darbepoetin alfa) was placed between the two periods to allow sufficient elimination of the drug administered in the previous period [19]. Blood samples for the PK assessment were obtained at predose and at 2, 4, 8, $12,24,36,48,72,96,120,168,216,264$, and $360 \mathrm{~h}$ postdose in each period in part 1 and at predose and 0.25, 0.5, $1,2,4,8,12,24,36,48,72,96,120,168,216$, and $264 \mathrm{~h}$ postdose in each period in part 2 . For the PD assessment, the Ret count (\%), hematocrit (Hct; \%), $\mathrm{Hb}(\mathrm{g} / \mathrm{L})$, and RBC count $\left(10^{6} / \mathrm{mm}^{3}\right)$ were measured at predose and $24,36,48$, $72,96,120,168,216,264$, and $360 \mathrm{~h}$ postdose in part 1 and at predose and 24, 36, 48, 72, 96, 120, 168, 216, and $264 \mathrm{~h}$ postdose in part 2 . We assessed the anti-drug antibody (ADA) formation after darbepoetin alfa administration only in period 1. By doing this, we could rule out the carry-over effect in immunogenicity assessment.

\subsection{Bioanalytical Methods}

Serum darbepoetin alfa concentrations were quantified by a validated enzyme-linked immunosorbent assay (ELISA) method with a Quantikine ${ }^{\circledR}$ IVD $^{\circledR}$ ELISA, a human EPO immunoassay kit (R\&D Systems Inc., Minneapolis, MN, US; Lot number: 323465) [21, 22]. The quantification of EPO was made without distinction between endogenous EPO and darbepoetin alfa. The calibration standard samples of seven different concentrations (except the blank sample) constructed the calibration curve. Calibration curves of the test and reference showed linearity between 0.156 and
$5 \mu \mathrm{g} / \mathrm{L}$, and the lower limit of quantification for darbepoetin alfa was $0.156 \mu \mathrm{g} / \mathrm{L}$. Samples expected to exceed the upper limit of the linear range were diluted before analysis with specimen diluent of the enzyme immunoassay kit. The intra- and inter-assay precision was $1.8 \%$ and $9.9 \%$, respectively. The back-calculated concentration ranged from 84.0 to $105.8 \%$ at the lower limit of quantification $(0.156 \mathrm{ng} / \mathrm{mL})$, 98.8 to $101.6 \%$ at the upper limit of quantification $(5 \mathrm{ng} /$ $\mathrm{mL}$ ), and 94.9 to $105.9 \%$ at the other concentrations.

To measure the ADA levels, the bridging ELISA method was used. The assay system utilized a biotin-labeled drug (test), a fluorescein-labeled drug, and an anti-fluorescein antibody. First, the positive control in human serum $(100 \mu \mathrm{L})$, the biotin-labeled drug $(100 \mu \mathrm{L})$, and the fluorescein-labeled drug $(100 \mu \mathrm{L})$ were incubated simultaneously for $1 \mathrm{~h}$ in a polypropylene 96 -well plate at $37^{\circ} \mathrm{C}$ with shaking and then incubated overnight at $4{ }^{\circ} \mathrm{C}$. This solution was then transferred to a streptavidin-coated microtiter plate, blocked with phosphate-buffered saline with Tween ${ }^{\circledR}$ 20 tablets, pH 7.4 (Takara Bio, Inc., Shiga, Japan) with $0.5 \%$ bovine serum albumin, and incubated for $1 \mathrm{~h}$ at room temperature. After removing the solution and washing, antifluorescein antibody and 3,3',5,5'-tetramethylbenzidine were reacted on a plate.

The analyses of the hematologic parameters for PD assessment were conducted in the Department of Laboratory Medicine, Samsung Medical Center (SMC; Seoul, Republic of Korea). The Ret count, Hct, Hb, and RBC count were determined by flow cytometry using a Sysmex XE-2100 Hematology Autoanalyzer (Sysmex Corporation, Kobe, Japan).

\subsection{Pharmacokinetic and Pharmacodynamic Analyses}

The non-compartmental PK analysis of darbepoetin alfa was performed with Phoenix ${ }^{\circledR}$ WinNonlin ${ }^{\circledR}$ (version 7.1.0; Certara USA, Inc., Princeton, NJ, USA). The $C_{\max }$ and the time to $C_{\max }\left(t_{\max }\right)$ were taken directly from the observed values. The $\mathrm{AUC}_{\text {last }}$ and the AUC from time zero to infinity $\left(\mathrm{AUC}_{\infty}\right)$ were calculated by the linear-up/ $\log$-down method. The elimination rate constant $\left(\lambda_{\mathrm{z}}\right)$ was estimated by a linear regression of the log-linear decline of the concentration-time curve. The $t_{1 / 2}$ was calculated as $\ln 2 / \lambda_{\mathrm{z}}$. The clearance $(\mathrm{CL})$ and apparent clearance $\left(\mathrm{CL}_{\mathrm{app}}\right)$ were calculated by dividing the administered dosage by the $\mathrm{AUC}_{\infty}$. The volume of distribution $(V \mathrm{~d})$ and apparent volume of distribution $\left(V \mathrm{~d}_{\text {app }}\right)$ were calculated by dividing the $C L$ and $C_{\text {app }}$ by $\lambda_{\mathrm{z}}$. Since the PK characteristics of darbepoetin alfa after SC or IV administration were 
assessed in different subjects in separate parts of the study, we did not assess the bioavailability of darbepoetin alfa.

The time courses of the Ret count, $\mathrm{Hct}, \mathrm{Hb}$, and RBC count were investigated and compared between the test and reference drugs as PD markers. The maximum effect $\left(E_{\max }\right)$ and the time to $E_{\max }\left(t_{\mathrm{Emax}}\right)$ were taken directly from the observed values. The AUC from time zero to the last point of quantifiable effect $\left(\mathrm{AUEC}_{\text {last }}\right)$ was calculated using the linear trapezoidal method.

\subsection{Safety Analysis}

All adverse events (AEs) were recorded on investigators' questionnaires or subjects' spontaneous reports. Physical examinations, vital-sign measurements, 12-lead ECGs, and laboratory testing (hematology, clinical chemistry, coagulation, and urinalysis) were performed at predefined, regular intervals throughout the studies and all clinically significant abnormal changes in the test results were reported as AEs. All AEs were assessed by the investigators with respect to severity, course, outcome, seriousness, and relationship to the study drug and were recorded regardless of the suspected relationship to the study drug. The clinical laboratory tests were performed by the Department of Laboratory Medicine at SMC. The laboratory is accredited by the College of American Pathologists, and quality control was ensured according to the internal standard operating procedures of SMC.

\subsection{Statistical Analysis}

Statistical analysis was carried out with $\mathrm{SAS}^{\circledR}$ Enterprise Guide $^{\circledR}$ (version 7.1; SAS Institute Inc., Cary, NC, USA). The descriptive statistics of PK and PD variables for each analyte were summarized by intervention. The PK comparison was performed using the $C_{\max }$ and $\mathrm{AUC}_{\text {last }}$. For the log-transformed $\mathrm{PK}$ parameters, linear mixed-effect analysis of variance was performed with fixed effects for the formulation, period, and sequence and a random effect for the subject nested for the sequence. The geometric mean ratio of the test to the comparator and the $90 \%$ confidence interval (CI) for each PK parameter was calculated. The test drug was considered to demonstrate a PK equivalence with the reference drug if the $90 \%$ CI for each PK parameter was within the range of $0.80-1.25$. The PD parameters were log-transformed and then the significance of the difference between the two interventions was tested using the analysis of covariance (linear mixed model) including predose concentration as a covariate. For $t_{\mathrm{Emax}}$, the significance of the difference between the two interventions was tested using the Wilcoxon signed rank test without log-transformation.

\section{Results}

\subsection{Demographics}

A total of 28 subjects were enrolled in both parts 1 and 2 . A summary of the demographic data according to the study part is shown in Table 1. There were five and nine subjects who were smokers in parts 1 and 2, respectively, and the

Table 1 Demographic characteristics

\begin{tabular}{|c|c|c|c|c|}
\hline \multirow[t]{2}{*}{ Variables } & \multicolumn{2}{|l|}{ Sequence } & \multirow[t]{2}{*}{ Total } & \multirow[t]{2}{*}{$p$ value $^{\mathrm{a}}$} \\
\hline & Reference $\rightarrow$ test & Test $\rightarrow$ reference & & \\
\hline \multicolumn{5}{|c|}{ Part 1: subcutaneous administration of darbepoetin alfa $60 \mu \mathrm{g}$} \\
\hline Number of subjects & 14 & 14 & 28 & \\
\hline Age (years) & $32.64 \pm 8.77$ & $31.50 \pm 7.29$ & $32.07 \pm 7.93$ & 0.7107 \\
\hline Height $(\mathrm{cm})$ & $173.29 \pm 4.66$ & $173.67 \pm 4.33$ & $173.48 \pm 4.42$ & 0.7940 \\
\hline Weight (kg) & $68.86 \pm 6.36$ & $68.24 \pm 6.24$ & $68.55 \pm 6.19$ & 0.8224 \\
\hline $\mathrm{BMI}\left(\mathrm{kg} / \mathrm{m}^{2}\right)$ & $22.93 \pm 1.88$ & $22.62 \pm 1.80$ & $22.77 \pm 1.81$ & 0.6628 \\
\hline \multicolumn{5}{|c|}{ Part 2: intravenous administration of darbepoetin alfa $60 \mu \mathrm{g}$} \\
\hline Number of subjects & 14 & 14 & 28 & \\
\hline Age (years) & $30.00 \pm 7.50$ & $29.07 \pm 9.09$ & $29.54 \pm 8.19$ & 0.7706 \\
\hline Height $(\mathrm{cm})$ & $171.41 \pm 7.41$ & $173.93 \pm 5.68$ & $172.67 \pm 6.60$ & 0.2868 \\
\hline Weight (kg) & $67.09 \pm 8.32$ & $70.40 \pm 7.76$ & $68.75 \pm 8.07$ & 0.3216 \\
\hline BMI $\left(\mathrm{kg} / \mathrm{m}^{2}\right)$ & $22.81 \pm 2.17$ & $23.22 \pm 1.65$ & $23.02 \pm 1.90$ & 0.5783 \\
\hline
\end{tabular}

Values are presented as the mean \pm standard deviation

$B M I$ body mass index

${ }^{\text {a }}$ Student's $t$ test 
mean (standard deviation) amounts of smoking were 7.0 (2.8) and 6.6 (3.5) cigarettes/day in parts 1 and 2, respectively. Demographic and other baseline characteristics were not significantly different between the two sequences in both parts. In part 1, there were two dropouts: one before and one after the investigational product administration. In part 2 , there were four dropouts: one before and three after receiving the investigational product. Hence, 26 and 24 subjects completed the study in parts 1 and 2 , respectively.

\subsection{Pharmacokinetic Analysis}

A summary of the PK parameters of darbepoetin alfa is presented in Table 2. The mean serum concentration-time profiles after SC or IV administration of the test or reference product are shown in Fig. 2.

\subsubsection{Part 1: Subcutaneous Administration}

The serum concentrations of darbepoetin alfa peaked at a median of approximately $24 \mathrm{~h}$ for the test and reference product after SC administration (Fig. 2a). The serum level of darbepoetin alfa decreased with similar elimination

Table 2 Summary of pharmacokinetic variables for darbepoetin alfa

\begin{tabular}{|c|c|c|}
\hline Variables & Test & Reference \\
\hline \multicolumn{3}{|c|}{ Part 1: subcutaneous administration of darbepoetin alfa $60 \mu \mathrm{g}$} \\
\hline Number of subjects & 27 & 26 \\
\hline$t_{\max }(\mathrm{h})^{\mathrm{a}}$ & $24.08(12-48)$ & $24.03(8-48)$ \\
\hline$C_{\max }(\mu \mathrm{g} / \mathrm{L})$ & $2.44 \pm 0.74$ & $2.64 \pm 0.81$ \\
\hline $\mathrm{AUC}_{\text {last }}(\mathrm{h} \cdot \mu \mathrm{g} / \mathrm{L})$ & $249.62 \pm 56.30$ & $262.68 \pm 57.42$ \\
\hline $\mathrm{AUC}_{\infty}(\mathrm{h} \cdot \mu \mathrm{g} / \mathrm{L})$ & $294.93 \pm 62.81$ & $310.37 \pm 79.18$ \\
\hline$t_{1 / 2}(\mathrm{~h})$ & $134.17 \pm 45.52$ & $135.57 \pm 62.53$ \\
\hline $\mathrm{CL}_{\text {app }}(\mathrm{L} / \mathrm{h})$ & $0.21 \pm 0.05$ & $0.21 \pm 0.05$ \\
\hline$V \mathrm{~d}_{\text {app }}(\mathrm{h})$ & $40.11 \pm 13.33$ & $37.86 \pm 12.08$ \\
\hline \multicolumn{3}{|c|}{ Part 2: intravenous administration of darbepoetin alfa $60 \mu \mathrm{g}$} \\
\hline Number of subjects & 25 & 26 \\
\hline$C_{\max }(\mu \mathrm{g} / \mathrm{L})$ & $17.78 \pm 2.34$ & $18.64 \pm 3.80$ \\
\hline $\mathrm{AUC}_{\text {last }}(\mathrm{h} \cdot \mu \mathrm{g} / \mathrm{L})$ & $466.86 \pm 83.46$ & $479.78 \pm 86.92$ \\
\hline $\mathrm{AUC}_{\infty}(\mathrm{h} \cdot \mu \mathrm{g} / \mathrm{L})$ & $505.14 \pm 99.72$ & $516.30 \pm 89.75$ \\
\hline$t_{1 / 2}(\mathrm{~h})$ & $121.43 \pm 59.75$ & $119.05 \pm 53.23$ \\
\hline $\mathrm{CL}(\mathrm{L} / \mathrm{h})$ & $0.12 \pm 0.02$ & $0.12 \pm 0.03$ \\
\hline$V \mathrm{~d}(\mathrm{~h})$ & $20.45 \pm 7.69$ & $20.48 \pm 9.77$ \\
\hline
\end{tabular}

Data are presented as the mean \pm standard deviation unless stated otherwise

$A U C_{\infty}$ area under the concentration-time curve from time zero to infinity, $A U C_{\text {last }}$ area under the concentration-time curve to the last measurable concentration, $C L$ clearance, $C L_{a p p}$ apparent clearance, $C_{\max }$ maximum serum concentration, $t_{1 / 2}$ terminal elimination half-life, $t_{\max }$ time to maximum observed serum concentration, $V d$ volume of distribution, $V d_{a p p}$ apparent volume of distribution

${ }^{\text {a }}$ Data presented as median (minimum-maximum) curves between interventions. The mean $\mathrm{AUC}_{\text {last }}$ and $C_{\max }$ values of the test product were $249.62 \mathrm{~h} \cdot \mu \mathrm{g} / \mathrm{L}$ and $2.44 \mu \mathrm{g} / \mathrm{L}$, respectively; the corresponding values of the reference product were $262.68 \mathrm{~h} \cdot \mu \mathrm{g} / \mathrm{L}$ and $2.64 \mu \mathrm{g} / \mathrm{L}$, respectively. The geometric mean ratios of the $\mathrm{AUC}_{\text {last }}$ and $C_{\max }$ between the test and reference product after SC administration were 0.9533 (90\% CI 0.9110-0.9976) and 0.9326 (90\% CI 0.8689-1.0009), respectively (Table 3 ). The differences between interventions of exposure after SC administration were not significant.

\subsubsection{Part 2: Intravenous Administration}

The serum level of darbepoetin alfa decreased with similar elimination curves after IV administration between interventions (Fig. 2b). The arithmetic means of the darbepoetin alfa $\mathrm{AUC}_{\text {last }}$ value for the reference and test were 479.78 and $466.86 \mathrm{~h} \cdot \mu \mathrm{g} / \mathrm{L}$, respectively, and the arithmetic means of the darbepoetin alfa $C_{\max }$ value for the reference and test were 18.64 and $17.78 \mu \mathrm{g} / \mathrm{L}$, respectively. The geometric mean ratios of the $\mathrm{AUC}_{\text {last }}$ and $C_{\text {max }}$ between the test and reference product after IV administration were 0.9798 (90\% CI $0.9205-1.0429)$ and 0.9701 (90\% CI 0.8883-1.0594), respectively (Table 3 ). There was no significant difference in exposure between the two interventions.

\subsection{Pharmacodynamic Analysis}

The mean Ret counts increased up to 168 and $120 \mathrm{~h}$ after the SC and IV drug administration and then decreased until the last observed time (Fig. 3). In both parts, the AUEC last and $E_{\max }$ of the PD analytes were comparable between the test and the reference product (Table 4). Moreover, the time courses for the changes in PD analytes were similar between the test and reference drug (Table 4; Fig. 3). The time-matched PK and PD markers presented a counterclockwise hysteresis, which suggests a time delay between the change in serum concentration of darbepoetin alfa and the PD response (Fig. 4). From the timepoints at which both PK and PD were measured, the highest level of darbepoetin alfa concentration and Ret count were observed at 24 and $168 \mathrm{~h}$ after administration of darbepoetin alfa, respectively, in both part 1 and part 2 .

\subsection{Safety}

A total of 54 subjects (part 1:27, part 2: 27) received at least one dose of the test or reference drug. The treatmentemergent AEs that occurred in two or more subjects are shown in Table 5. No serious AE- and AE-related dropouts occurred during the study. All AEs were mild to moderate in severity and were recovered without sequelae. Frequencies of treatment-emergent AEs were similar between 
Fig. 2 Mean serum concentration-time profiles of darbepoetin alfa after a subcutaneous and b intravenous administration of the test or reference formulation. Note: bars represent standard deviations
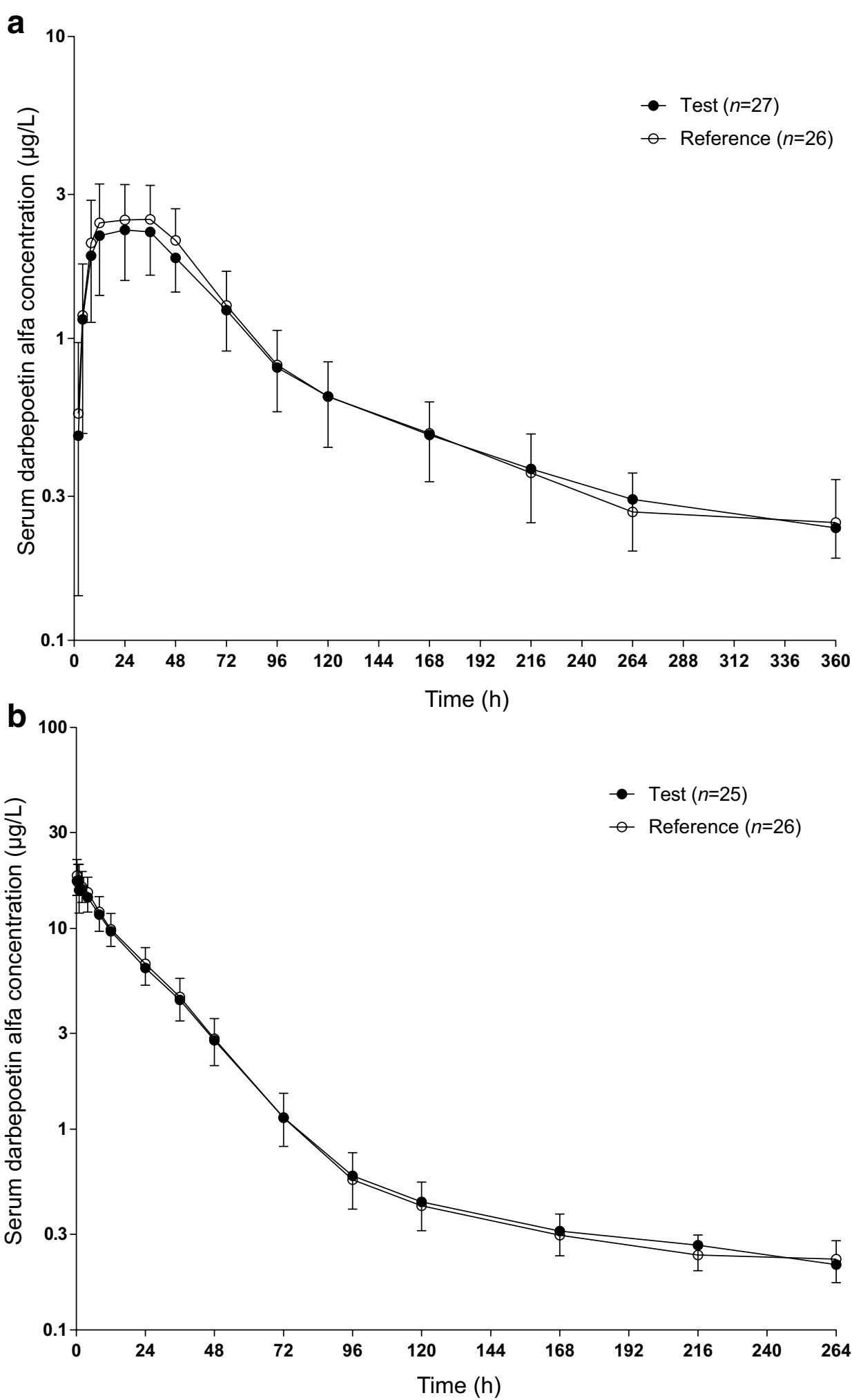

the test and reference drug in parts $1(p=0.4152)$ and 2 $(p=0.2528)$. Clinical laboratory evaluation of hematology, blood chemistry, and urinalysis throughout the study showed no unexpected changes that could be attributed to the test and reference drugs. There was no clinically significant finding in the vital signs, ECGs, and physical examination results in all interventions. The ADA reactivity was negative for all samples from both intervention groups regardless of 
Table 3 Pharmacokinetic comparison of darbepoetin alfa between interventions

\begin{tabular}{|c|c|c|c|}
\hline \multirow[t]{2}{*}{ Variables } & \multicolumn{2}{|c|}{ Geometric least square mean (CV) } & \multirow{2}{*}{$\begin{array}{l}\text { Geometric mean ratio } \\
(90 \% \text { confidence } \\
\text { interval })^{\mathrm{a}}\end{array}$} \\
\hline & Test & Reference & \\
\hline \multicolumn{4}{|c|}{ Part 1: subcutaneous administration of darbepoetin alfa $60 \mu \mathrm{g}$} \\
\hline Number of subjects & 27 & 26 & \\
\hline $\mathrm{AUC}_{\text {last }}(\mathrm{h} \cdot \mu \mathrm{g} / \mathrm{L})$ & $241.13(22.56)$ & $252.95(21.86)$ & $0.9533(0.9110-0.9976)$ \\
\hline$C_{\max }(\mu \mathrm{g} / \mathrm{L})$ & $2.35(30.17)$ & $2.52(30.69)$ & $0.9326(0.8698-1.0009)$ \\
\hline \multicolumn{4}{|c|}{ Part 2: intravenous administration of darbepoetin alfa $60 \mu \mathrm{g}$} \\
\hline Number of subjects & 25 & 26 & \\
\hline $\mathrm{AUC}_{\text {last }}(\mathrm{h} \cdot \mu \mathrm{g} / \mathrm{L})$ & $457.93(17.88)$ & $467.36(18.12)$ & $0.9798(0.9205-1.0429)$ \\
\hline$C_{\max }(\mu \mathrm{g} / \mathrm{L})$ & $17.97(13.16)$ & $18.52(20.38)$ & $0.9701(0.8883-1.0594)$ \\
\hline
\end{tabular}

$A U C_{\text {last }}$ area under the concentration-time curve to the last measurable concentration, $C_{\max }$ maximum serum concentration, $C V$ coefficient of variation

${ }^{\text {a }}$ Transformed back to the original scale after statistical analysis using log-transformed data
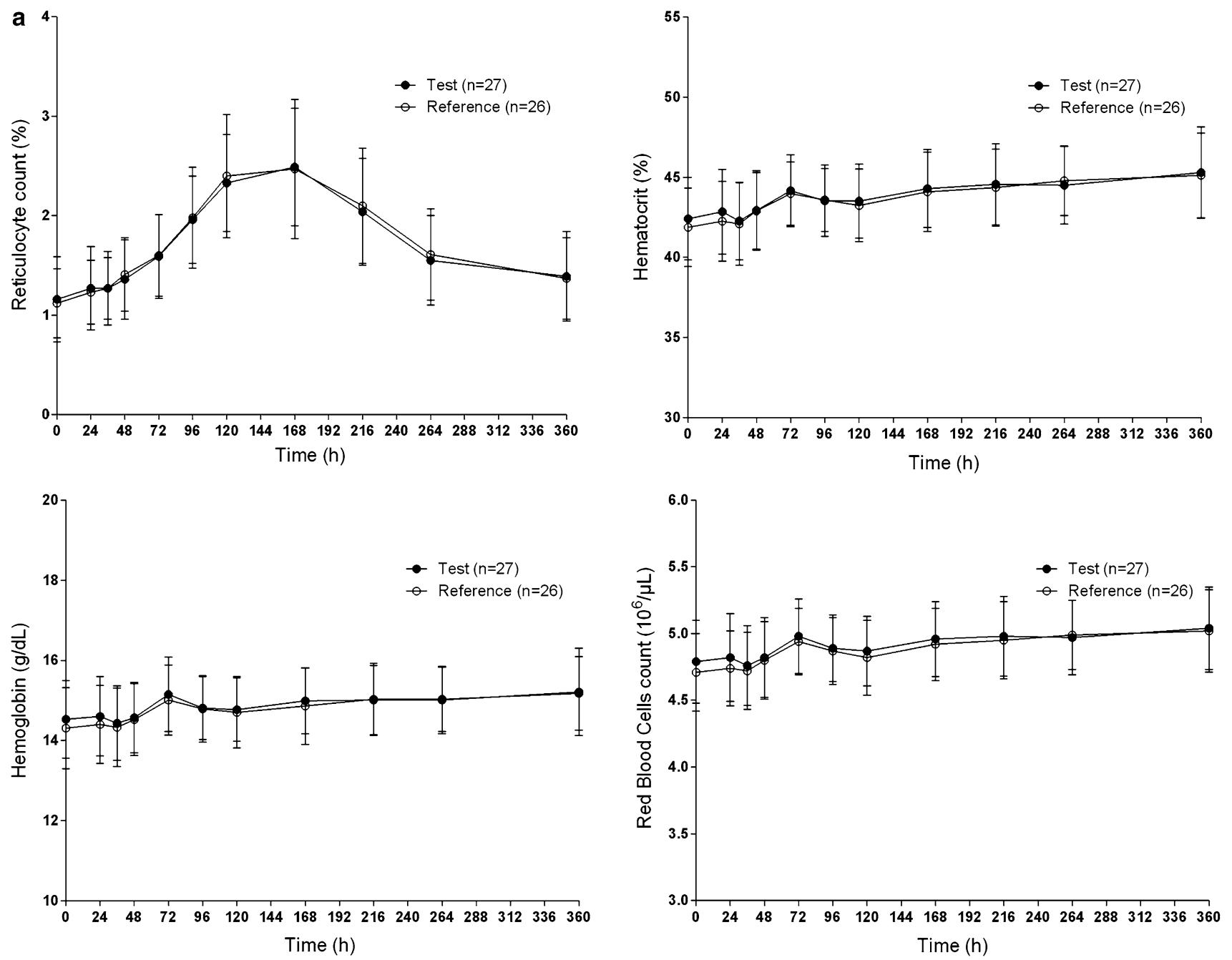

Fig. 3 Mean pharmacodynamic variable-time profiles of darbepoetin alfa after a subcutaneous and $\mathbf{b}$ intravenous administration of the test or reference formulation. Note: bars represent standard deviations 

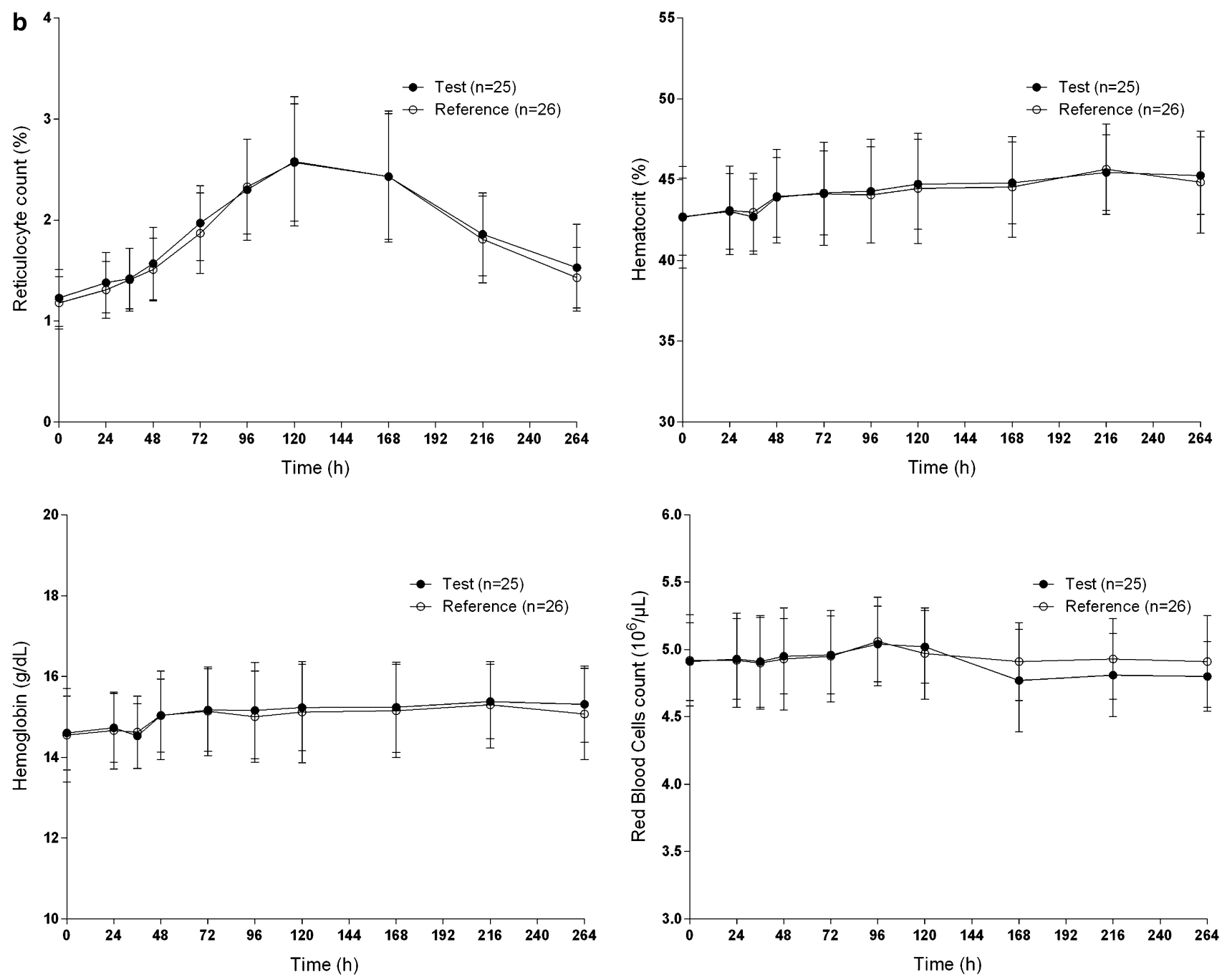

Fig. 3 (continued)

administration route. Administration of the test drug given as a single SC or IV injection was safe and well-tolerated in healthy male subjects and the frequency of AEs was similar to that in the reference drug.

\section{Discussion}

This study was designed to evaluate the PK, PD, and safety profiles of test and reference darbepoetin alfa given as a single SC or IV injection in healthy male subjects. The test darbepoetin alfa exhibited comparable safety, PK, and PD profiles to the reference drug in both administration routes.

For the PKs, the CIs of the geometric mean ratios (test to reference) for $C_{\max }$ and $\mathrm{AUC}_{\text {last }}$ fell within the acceptance criteria of $0.80-1.25$ with both SC and IV administration. The inter-subject variabilities of PK variables for the test drug were similar to those for the reference drug in both administration routes. The $t_{1 / 2}$ of darbepoetin alfa was longer following SC injection than following IV injection for the test drug, which is consistent with the previously reported results for the reference product [19,23]. The $t_{1 / 2}$ of darbepoetin alfa after SC administration reflects flip-flop kinetics [23]. In this study, the $t_{1 / 2}$ of the reference darbepoetin alfa following IV injection was $119.05 \mathrm{~h}$, which is four times more than that of a previous report (25.3 h) [19]. This study employed more protracted sampling periods (up to $360 \mathrm{~h})$ than the previous study $(96 \mathrm{~h})$ and the $t_{1 / 2}$ calculated from data with the same last timepoint $(96 \mathrm{~h})$ as the previous study is $20.4 \mathrm{~h}$. The $t_{1 / 2}$ of darbepoetin alfa in healthy subjects after SC administration is not reported. For reference, the $t_{1 / 2}$ was reported to be $48.8 \mathrm{~h}$ in dialysis patients with blood sampling up to $168 \mathrm{~h}$ after SC administration of darbepoetin alfa [24]. Meanwhile, since the quantification of EPO was made without distinction between endogenous EPO and darbepoetin alfa, correction to a baseline value was 
Table 4 Summary of pharmacodynamic variables for darbepoetin alfa between interventions

\begin{tabular}{|c|c|c|c|}
\hline Variables & Test & Reference & $p$ value $^{\mathrm{a}}$ \\
\hline \multicolumn{4}{|c|}{ Part 1 , subcutaneous administration of darbepoetin alfa $60 \mu \mathrm{g}$} \\
\hline Number of subjects & 27 & 26 & \\
\hline \multicolumn{4}{|l|}{ Reticulocyte count } \\
\hline $\operatorname{AUEC}_{\text {last }}(\mathrm{h} \cdot \%)$ & $623.5(23.7)$ & $628.9(24.3)$ & 0.5159 \\
\hline$E_{\max }(\%)$ & $2.45(22.6)$ & $2.47(26.2)$ & 0.6802 \\
\hline$t_{\text {Emax }}(\mathrm{h})^{\mathrm{b}}$ & $168.0(95.9-168.7)$ & $168.0(119.7-168.9)$ & 0.3426 \\
\hline \multicolumn{4}{|l|}{ Hematocrit } \\
\hline $\mathrm{AUEC}_{\text {last }}(\mathrm{h} \cdot \%)$ & $15,866(5.07)$ & $15,833(4.80)$ & 0.6694 \\
\hline$E_{\max }(\%)$ & $46.1(5.24)$ & $45.8(4.39)$ & 0.4557 \\
\hline$t_{\text {Emax }}(\mathrm{h})^{\mathrm{b}}$ & $168.0(95.9-168.7)$ & $264.1(72.0-361.2)$ & 0.9696 \\
\hline \multicolumn{4}{|l|}{ Hemoglobin } \\
\hline $\mathrm{AUEC}_{\text {last }}(\mathrm{h} \cdot \mathrm{g} / \mathrm{dL})$ & $5371(5.37)$ & $5353(5.49)$ & 0.5707 \\
\hline$E_{\max }(\mathrm{g} / \mathrm{dL})$ & $15.6(5.58)$ & $15.5(5.04)$ & 0.9713 \\
\hline$t_{\text {Emax }}(\mathrm{h})^{\mathrm{b}}$ & $263.9(0.0-360.9)$ & $264.1(24.0-361.2)$ & 0.6238 \\
\hline \multicolumn{4}{|l|}{ Red blood cell count } \\
\hline $\operatorname{AUEC}_{\text {last }}\left(\mathrm{h} \cdot 10^{6} / \mu \mathrm{L}\right)$ & $1776(5.34)$ & $1767(5.20)$ & 0.9433 \\
\hline$E_{\max }\left(10^{6} / \mu \mathrm{L}\right)$ & $5.15(5.58)$ & $5.11(4.83)$ & 0.4708 \\
\hline$t_{\text {Emax }}(\mathrm{h})^{\mathrm{b}}$ & $263.5(24.0-360.9)$ & $264.6(72.0-361.2)$ & 0.7127 \\
\hline \multicolumn{4}{|c|}{ Part 2: intravenous administration of darbepoetin alfa $60 \mu \mathrm{g}$} \\
\hline Number of subjects & 25 & 26 & \\
\hline \multicolumn{4}{|l|}{ Reticulocyte count } \\
\hline $\operatorname{AUEC}_{\text {last }}(\mathrm{h} \cdot \%)$ & $510.2(19.5)$ & $500.5(20.0)$ & 0.0735 \\
\hline$E_{\max }(\%)$ & $2.65(18.6)$ & $2.60(21.3)$ & 0.4007 \\
\hline$t_{\text {Emax }}(\mathrm{h})^{\mathrm{b}}$ & $120.1(72.0-168.8)$ & $120.1(96.2-168.6)$ & 0.7174 \\
\hline \multicolumn{4}{|l|}{ Hematocrit } \\
\hline $\mathrm{AUEC}_{\text {last }}(\mathrm{h} \cdot \%)$ & $11,735(5.19)$ & $11,705(6.39)$ & 0.6236 \\
\hline$E_{\max }(\%)$ & $46.3(5.47)$ & $46.2(6.36)$ & 0.7122 \\
\hline$t_{\text {Emax }}(\mathrm{h})^{\mathrm{b}}$ & $215.9(48.0-264.3)$ & $215.6(36.0-264.5)$ & 0.6151 \\
\hline \multicolumn{4}{|l|}{ Hemoglobin } \\
\hline $\mathrm{AUEC}_{\text {last }}(\mathrm{h} \cdot \mathrm{g} / \mathrm{dL})$ & $3995(6.11)$ & $3970(6.99)$ & 0.3561 \\
\hline$E_{\max }(\mathrm{g} / \mathrm{dL})$ & $15.7(6.53)$ & $15.7(7.06)$ & 0.6233 \\
\hline$t_{\text {Emax }}(\mathrm{h})^{\mathrm{b}}$ & $168.1(48.1-264.3)$ & $120.1(0.0-264.5)$ & 0.7063 \\
\hline \multicolumn{4}{|l|}{ Red blood cell count } \\
\hline $\operatorname{AUEC}_{\text {last }}\left(\mathrm{h} \cdot 10^{6} / \mu \mathrm{L}\right)$ & $1304(5.31)$ & $1302(6.50)$ & 0.5796 \\
\hline$E_{\max }\left(10^{6} / \mu \mathrm{L}\right)$ & $5.13(5.50)$ & $5.12(6.54)$ & 0.2600 \\
\hline$t_{\text {Emax }}(\mathrm{h})^{\mathrm{b}}$ & $168.8(48.1-264.3)$ & $191.9(24.0-264.5)$ & 0.6418 \\
\hline
\end{tabular}

Data are presented as the geometric least square mean (coefficient of variation) unless specified otherwise $A U E C_{\text {last }}$ area under the effect-time curve from time zero to the last point of quantifiable effect, $E_{\text {max }}$ maximum effect, $t_{\text {Emax }}$ time to maximum effect

${ }^{a}$ Linear mixed model with intervention, period, sequence, group, and sequence-nested subject effect and predose value as a covariate for $\mathrm{AUEC}_{\text {last }}$ and $E_{\text {max }}$, while the Wilcoxon signed rank test was the source for $t_{\mathrm{Emax}}$

${ }^{\mathrm{b}}$ Data presented as median (minimum-maximum)

plausible for PK analysis. However, in this study, baseline correction was not carried out because most baseline values were below the lower limit of quantification.

It is recommended that darbepoetin alfa be administered once a week or every 2 weeks for patients with CKD on dialysis and with 4-week intervals for patients with CKD not on dialysis $[25,26]$. The Hct, $\mathrm{Hb}$, and $\mathrm{RBC}$ counts that reflect erythropoiesis increased up to $360 \mathrm{~h}$, while the Ret counts recovered to baseline levels after an initial incremental increase following SC injection of darbepoetin alfa. Following IV injection, $\mathrm{Hct}, \mathrm{Hb}$, and $\mathrm{RBC}$ counts increased for $216 \mathrm{~h}$ and then decreased thereafter, while the Ret 
a

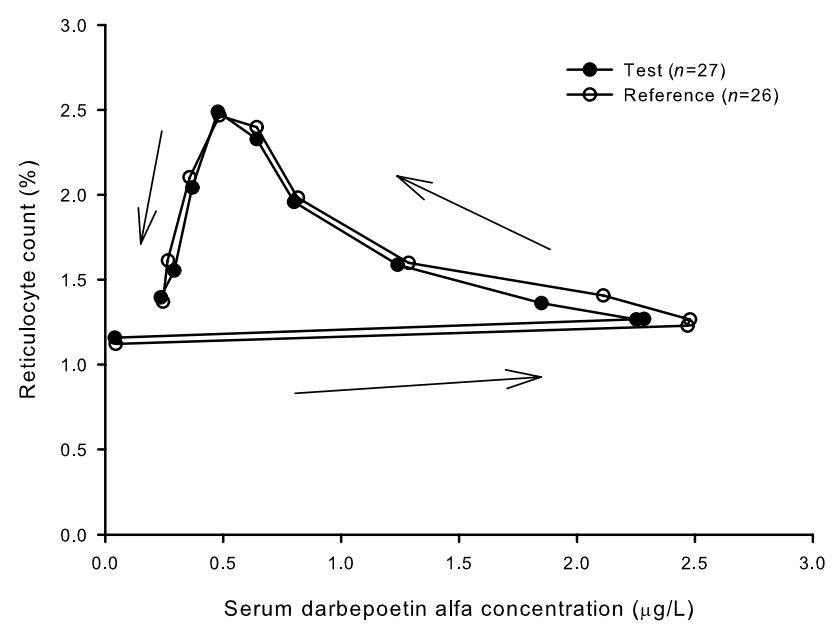

b

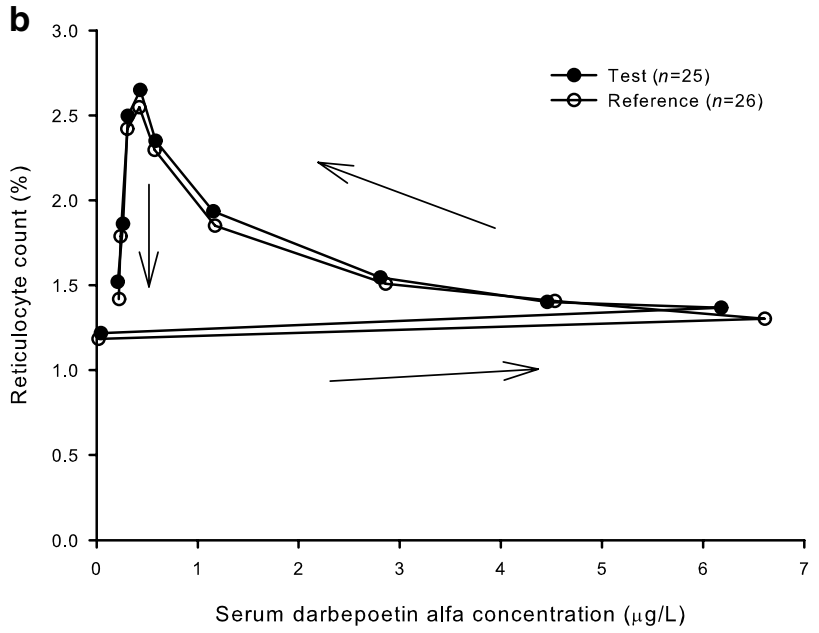

Fig. 4 Relationship between mean serum darbepoetin alfa concentration and reticulocyte count after $\mathbf{a}$ subcutaneous and $\mathbf{b}$ intravenous administration of the test or reference formulation. Note: the symbols represent the mean pharmacokinetic-pharmacodynamic relationship at predose and $24,36,48,72,96,120,168,216,264$, and $360 \mathrm{~h}$ after subcutaneous administration, and at predose and $24,36,48,72,96$, $120,168,216$, and $264 \mathrm{~h}$ after intravenous administration

count-time profile was similar to that of the SC route. This may result from slow absorption along with the long duration of SC administration, which leads to sustained drug exposure and persistence of the effect. However, IV administration of darbepoetin alfa also showed an erythropoietic effect over sufficient time in this study. By examining the response after administration, in this study we again confirmed the appropriateness of the darbepoetin alfa regimens, including the IV route recommendation, for patients on hemodialysis [25].
Intensive PK-PD studies of darbepoetin alfa in healthy subjects have not been reported. However, we verified the relationship and time-dependent changes in the PK-PD relationship of darbepoetin alfa, revealing it to be a counterclockwise hysteresis loop. This characteristic of rHuEPO had already been reported in previous studies [22, 27]. The counter-clockwise hysteresis implies that there is a delay in equilibrium between the serum drug concentration and the PD effect [28] related to the maturation of normoblasts in bone marrow (3-7 days) [29-31].

The PKs and PDs of darbepoetin alfa are well-established in patient populations and healthy subjects. Thus, regarding assessment of rHuEPO biosimilars, PK and PD results with sufficient evidence to support a conclusion of no clinically meaningful differences may make a comparative efficacy study unnecessary in cases where there is a meaningful correlation between the PK and PD results and clinical effectiveness [32]. Although there are some patients who are resistant to rHuEPO, the cause of this is well-known and it has been established that rHuEPO shows a dose-proportional erythropoietic effect in about $90 \%$ of anemia patients [33, 34]. Because of this, in general, the PK and erythropoetic responses to rHuEPO in patients with CKD are not expected to differ from those in healthy subjects $[35,36]$. For reference, the PK/PD assessments in healthy subjects were considered the most perceptive in identifying the PK and PD response characteristics for a proposed biosimilar of epoetin alfa [37]. Furthermore, there is a known correlation between the $\mathrm{Hb}$ response and the improvement in quality of life after administration of darbepoetin alfa [38]. This study provides good evidence to enable prediction of the efficacy and effectiveness in patients receiving darbepoetin alfa with regards to $\mathrm{Hb}$ response and quality of life.

Administration of a single dose of test and reference darbepoetin alfa was safe and well-tolerated in healthy male subjects. Observed AEs were consistent with the AEs reported in the prescribing information of $\mathrm{NESP}^{\circledR}$ and no unexpected AEs were found following the administration of the test.

\section{Conclusion}

The test darbepoetin alfa had similar PK and PD characteristics as the reference drug and the safety and immunogenicity profile was similar between the two interventions. In terms of PDs, the serum concentration of darbepoetin alfa and erythropoietic response showed hysteretic relationships that were comparable between the two interventions. The similarities of the PK and PD properties and the safety 
Table 5 Treatment-emergent adverse events reported in two or more subjects between interventions

\begin{tabular}{lll}
\hline Symptoms and signs & Test & Reference \\
\hline Part 1: subcutaneous administration of darbepoetin alfa $60 \mu \mathrm{g}$ & $n=27$ & $n=26$ \\
Back pain & $1(1)$ & $2(2)$ \\
Headache & $1(1)$ & $2(2)$ \\
Injection-site bruising & $3(3)$ & $4(4)$ \\
Nasopharyngitis & $1(1)$ & $2(2)$ \\
Neutrophil count decreased & $2(2)$ & $n=27$ \\
Part 2: intravenous administration of darbepoetin alfa $60 \mu \mathrm{g}$ & $n=25$ & $1(1)$ \\
Blood creatine phosphokinase increased & $2(2)$ & $2(2)$ \\
Headache & $2(2)$ & $2(2)$ \\
Nasopharyngitis & $2(2)$ & $1(1)$ \\
Neutrophil count decreased & $1(1)$ \\
Myalgia &
\end{tabular}

Data presented as the number of subjects (number of events)

profiles of the test and reference drug imply that they can be used interchangeably.

Author contributions This study was designed and conducted by $\mathrm{TH}$, $\mathrm{J}-\mathrm{WK}, \mathrm{WH}$, and J-RK. The sponsor was not involved in the study design or in the analysis and interpretation of the data. All of the coauthors participated in either writing or reviewing the manuscript.

\section{Compliance with Ethical Standards}

Funding This study was sponsored by CJ HealthCare Corp., Seoul, Republic of Korea.

Conflict of interest Seokuee Kim, Taegon Hong, Jae-Wook Ko, Wooseong Huh, and Jung-Ryul Kim declare that they have no conflict of interest.

Ethical approval The study protocol was reviewed and approved by the health authorities from the Ministry of Food and Drug Safety of South Korea and the Institutional Review Board of Samsung Medical Center. Written informed consents were obtained from all subjects included in this study.

Open Access This article is distributed under the terms of the Creative Commons Attribution-NonCommercial 4.0 International License (http://creativecommons.org/licenses/by-nc/4.0/), which permits any noncommercial use, distribution, and reproduction in any medium, provided you give appropriate credit to the original author(s) and the source, provide a link to the Creative Commons license, and indicate if changes were made.

\section{References}

1. Tsagalis G. Renal anemia: a nephrologist's view. Hippokratia. 2011;15(Suppl 1):39-43.
2. Babitt JL, Lin HY. Mechanisms of anemia in CKD. J Am Soc Nephrol. 2012;23(10):1631-4. https://doi.org/10.1681/ ASN.2011111078.

3. Vansteenkiste J, Pirker R, Massuti B, Barata F, Font A, Fiegl M, et al. Double-blind, placebo-controlled, randomized phase III trial of darbepoetin alfa in lung cancer patients receiving chemotherapy. J Natl Cancer Inst. 2002;94(16):1211-20.

4. Cazzola M, Mercuriali F, Brugnara C. Use of recombinant human erythropoietin outside the setting of uremia. Blood. 1997;89(12):4248-67.

5. Markham A, Bryson HM. Epoetin alfa: a review of its pharmacodynamic and pharmacokinetic properties and therapeutic use in nonrenal applications. Drugs. 1995;49(2):232-54.

6. Sowade B, Sowade O, Mocks J, Franke W, Warnke H. The safety of treatment with recombinant human erythropoietin in clinical use: a review of controlled studies. Int J Mol Med. 1998;1(2):303-14.

7. Koury MJ, Bondurant MC. Control of red cell production: the roles of programmed cell death (apoptosis) and erythropoietin. Transfusion. 1990;30(8):673-4.

8. Graber SE, Krantz SB. Erythropoietin and the control of red cell production. Annu Rev Med. 1978;29:51-66. https://doi. org/10.1146/annurev.me.29.020178.000411.

9. Wu H, Liu X, Jaenisch R, Lodish HF. Generation of committed erythroid BFU-E and CFU-E progenitors does not require erythropoietin or the erythropoietin receptor. Cell. 1995;83(1):59-67.

10. Koury MJ, Bondurant MC. The mechanism of erythropoietin action. Am J Kidney Dis. 1991;18(4 Suppl 1):20-3.

11. Kliger AS, Fishbane S, Finkelstein FO. Erythropoietic stimulating agents and quality of a patient's life: individualizing anemia treatment. Clin J Am Soc Nephrol. 2012;7(2):354-7. https://doi. org/10.2215/CJN.11961111.

12. Locatelli F, Nissenson AR, Barrett BJ, Walker RG, Wheeler $\mathrm{DC}$, Eckardt KU, et al. Clinical practice guidelines for anemia in chronic kidney disease: problems and solutions. A position statement from Kidney Disease: Improving Global Outcomes (KDIGO). Kidney Int. 2008;74(10):1237-40. https://doi. org/10.1038/ki.2008.299.

13. Martinez-Castelao A, Cases A, Carballada AT, Iranzo JT, Bronsoms J, Valles-Prats M, et al. Clinical impact of the ERBP Working Group 2010 Recommendations for the anemia management in chronic kidney disease not on dialysis: ACERCA study. 
Nefrologia. 2015;35(2):179-88. https://doi.org/10.1016/j.nefro 2015.05.018.

14. Egrie JC, Browne JK. Development and characterization of novel erythropoiesis stimulating protein (NESP). Nephrol Dial Transpl. 2001;16(Suppl 3):3-13.

15. Egrie JC. Novel erythropoiesis stimulating protein (NESP) has a longer serum half-life and greater in vivo biological activity compared to recombinant human erythropoietin (rHuEPO). Blood. 1997;90:56a

16. Joy MS. Darbepoetin alfa: a novel erythropoiesis-stimulating protein. Ann Pharmacother. 2002;36(7-8):1183-92. https://doi. org/10.1345/aph.1A416.

17. Allon M, Kleinman K, Walczyk M, Kaupke C, Messer-Mann L, Olson K, et al. Pharmacokinetics and pharmacodynamics of darbepoetin alfa and epoetin in patients undergoing dialysis. Clin Pharmacol Ther. 2002;72(5):546-55. https://doi.org/10.1067/ mcp.2002.128374.

18. Ministry of Food and Drug Safety of Korea. Korean good clinical practices guideline (in Korean). Revised in 2018. http://www. law.go.kr/LSW//1sBylInfoP.do?bylSeq=7418202\&lsiSeq=20333 $8 \&$ efYd $=20180425$. Accessed 15 Oct 2018.

19. Application no. (BLA) 103951-ARANESP. Center for Biologics Evaluation and Research, Food and Drug Administration; 2001. https://www.accessdata.fda.gov/drugsatfda_docs/label /2011/103951Orig1s5173SumR.pdf. Accessed 7 Aug 2018.

20. Galgatte UC, Jamdade VR, Aute PP, Chaudhari PD. Study on requirements of bioequivalence for registration of pharmaceutical products in USA, Europe and Canada. Saudi Pharm J. 2014;22(5):391-402. https://doi.org/10.1016/j.jsps.2013.05.001.

21. Glaspy J, Henry D, Patel R, Tchekmedyian S, Applebaum $\mathrm{S}$, Berdeaux D, et al. Effects of chemotherapy on endogenous erythropoietin levels and the pharmacokinetics and erythropoietic response of darbepoetin alfa: a randomised clinical trial of synchronous versus asynchronous dosing of darbepoetin alfa. Eur J Cancer. 2005;41(8):1140-9. https://doi.org/10.1016/j. ejca.2005.01.021

22. Yoon S, Rhee SJ, Heo SJ, Oh TY, Yoon SH, Cho JY, et al. Comparable pharmacokinetics and pharmacodynamics of two epoetin alfa formulations Eporon((R)) and $\operatorname{Eprex}((\mathrm{R}))$ following a single subcutaneous administration in healthy male volunteers. Drug Des Dev Ther. 2017;11:3127-35. https://doi.org/10.2147/DDDT. S142673.

23. Macdougall IC, Padhi D, Jang G. Pharmacology of darbepoetin alfa. Nephrol Dial Transpl. 2007;22(Suppl 4):iv2-9. https://doi. org/10.1093/ndt/gfm160.

24. Macdougall IC, Gray SJ, Elston O, Breen C, Jenkins B, Browne J, et al. Pharmacokinetics of novel erythropoiesis stimulating protein compared with epoetin alfa in dialysis patients. J Am Soc Nephrol. 1999;10(11):2392-5.

25. Amgen. Prescribing information: ARANESP ${ }^{\circledR} ; 2001$. https:// www.accessdata.fda.gov/drugsatfda_docs/label/2011/103951Orig 1s5173_103951Orig1s5258lbl.pdf. Accessed 7 Aug 2018.
26. Macdougall IC. Optimizing the use of erythropoietic agentspharmacokinetic and pharmacodynamic considerations. Nephrol Dial Transpl. 2002;17(Suppl 5):66-70.

27. Souillard A, Audran M, Bressolle F, Gareau R, Duvallet A, Chanal JL. Pharmacokinetics and pharmacodynamics of recombinant human erythropoietin in athletes. Blood sampling and doping control. Br J Clin Pharmacol. 1996;42(3):355-64.

28. Girard P, Boissel JP. Clockwise hysteresis or proteresis. J Pharmacokinet Biopharm. 1989;17(3):401-2.

29. Koepke JF, Koepke JA. Reticulocytes. Clin Lab Haematol. 1986;8(3):169-79.

30. Krzyzanski W, Jusko WJ, Wacholtz MC, Minton N, Cheung WK. Pharmacokinetic and pharmacodynamic modeling of recombinant human erythropoietin after multiple subcutaneous doses in healthy subjects. Eur J Pharm Sci. 2005;26(3-4):295-306. https ://doi.org/10.1016/j.ejps.2005.06.010.

31. Varlet-Marie E, Gaudard A, Audran M, Bressolle F. Pharmacokinetics/pharmacodynamics of recombinant human erythropoietins in doping control. Sports Med. 2003;33(4):301-15.

32. U.S. Department of Health and Human Services Food and Drug Administration Center for Drug Evaluation and Research and Center for Biologics Evaluation and Research. Guidance for industry: scientific considerations in demonstrating biosimilarity to a reference product; 2015 . https://www.fda.gov/downloads/ drugs/guidances/ucm291128.pdf. Accessed 7 Aug 2018.

33. Alves MT, Vilaca SS, Carvalho M, Fernandes AP, Dusse LM, Gomes KB. Resistance of dialyzed patients to erythropoietin. Rev Bras Hematol Hemoter. 2015;37(3):190-7. https://doi. org/10.1016/j.bjhh.2015.02.001.

34. Park JS. Hyporesponsiveness of erythropoietin in end stage renal disease patients. Korean J Med. 2000;58(5):494-6.

35. Flaharty KK, Caro J, Erslev A, Whalen JJ, Morris EM, Bjornsson TD, et al. Pharmacokinetics and erythropoietic response to human recombinant erythropoietin in healthy men. Clin Pharmacol Ther. 1990;47(5):557-64.

36. McGowan T, Vaccaro NM, Beaver JS, Massarella J, Wolfson M. Pharmacokinetic and pharmacodynamic profiles of extended dosing of epoetin alfa in anemic patients who have chronic kidney disease and are not on dialysis. Clin J Am Soc Nephrol. 2008;3(4):1006-14. https://doi.org/10.2215/CJN.05671207.

37. FDA advisory committee briefing document: Epoetin hospira, a proposed biosimilar to epogen/procrit (epoetin alfa); 2017. https:// www.fda.gov/downloads/AdvisoryCommittees/CommitteesMeeti ngMaterials/Drugs/OncologicDrugsAdvisoryCommittee/UCM55 9968.pdf. Accessed 7 Aug 2018.

38. Kotasek D, Steger G, Faught W, Underhill C, Poulsen E, Colowick $\mathrm{AB}$, et al. Darbepoetin alfa administered every 3 weeks alleviates anaemia in patients with solid tumours receiving chemotherapy; results of a double-blind, placebo-controlled, randomised study. Eur J Cancer. 2003;39(14):2026-34. 